\title{
Continuation of long term treatment with hydroxychloroquine in systemic lupus erythematosus and rheumatoid arthritis
}

\author{
E F Morand, P I McCloud, G O Littlejohn
}

\begin{abstract}
Background Hydroxychloroquine is used for the treatment of rheumatoid arthritis (RA) and systemic lupus erythematosus (SLE). Long term studies have shown a high rate of termination of hydroxychloroquine treatment in patients with RA. Although it has been shown that discontinuation of treatment with hydroxychloroquine is associated with exacerbation of SLE, long term maintenance rates of treatment with hydroxychloroquine in patients with SLE have not been investigated.
\end{abstract}

Methods Hydroxychloroquine use in patients with RA and SLE in a group of patients in a single community rheumatology practice was studied. Information was drawn from a computer drug use database containing details of the beginning and end of treatment. Data were analysed using life table methods.

Results Four hundred and three treatment episodes (366 patients with RA, 37 patients with SLE) were observed over eight years. In patients with RA, the cumulative probability of discontinuing treatment was $37 \%$ at 12 months and $54 \%$ at 24 months. In contrast, hydroxychloroquine treatment of patients with SLE continued over significantly longer periods of time $(\mathbf{p}<0.001)$; the discontinuation probabilities at 12 and 24 months were 8 and $24 \%$ respectively. Treatment terminations were predominantly for inefficacy; terminations for toxicity were limited to the first 19 months of treatment. No ocular toxicity was observed.

Conclusions Treatment of patients with RA in a community rheumatology practice with hydroxychloroquine has a low probability of long term continuation, mostly because of inadequate control of disease manifestations rather than toxicity. In patients with SLE, treatment with hydroxychloroquine has a significantly higher probability of long term continuation.

Rheumatology Unit, Monash Medical Centre, Clayton, Victoria,

Australia

E F Morand

G O Littlejohn

Department of Mathematics, Monash University, Clayton, Victoria, Australia

P I McCloud

Correspondence to: Dr G O Littlejohn, Rheumatology Unit, Monash Medical Centre, Locked Bag No 29, Clayton, Victoria 3168, Australia.

Accepted for publication 1 July 1992 studies of the use of antimalarial drugs since the 1950s have suggested clinical benefits associated with these, ${ }^{89}$ and longer term prospective studies, of up to one year, continue to be published. ${ }^{10}$ Prolonged continuous use of slow acting antirheumatic drugs is increasingly recommended in patients with $R A,{ }^{11}$ but several studies which address the long term treatment of RA have illustrated that the probability of long term use of many slow acting antirheumatic drugs, including hydroxychloroquine, is low. ${ }^{12-15}$ Consideration of the long term use of hydroxychloroquine may also be of importance in patients with SLE. A study by the Canadian hydroxychloroquine study group has reported that withdrawal of hydroxychloroquine in a group of patients with stable SLE was associated with an increased likelihood of a clinical flare. ${ }^{3}$

The measurement, in observational studies, of the retention rate of treatment is a useful way to assess the use of slow acting antirheumatic drugs in $\mathrm{RA}^{16}$ these methods have not been used to examine the use of hydroxychloroquine in patients with SLE. In an attempt to address the issue of the long term use of treatment with hydroxychloroquine in RA and SLE, we have undertaken an analysis of hydroxychloroquine treatment in patients with RA and SLE in a community rheumatology practice.

\section{Patients and methods}

All patients from a single community based rheumatology practice who received treatment with slow acting antirheumatic drugs between July 1980 and September 1989 were studied. Treatment details, including age, sex, diagnosis, dates of starting and stopping drug treatment, and reason(s) for stopping treatment were recorded on a computer database. Rheumatoid arthritis was defined according to the American Rheumatism Association (ARA) guidelines current for the time. ${ }^{17} 18$ Systemic lupus erythematosus was defined in patients with either four ARA criteria for SLE ${ }^{19}$ or three criteria plus other supporting features for the diagnosis of SLE, in the absence of alternative diagnoses. Indications for the use of hydroxychloroquine were persisting synovitis (RA and SLE), rash, or constitutional symptoms (SLE). Doses ranged from 200 to $400 \mathrm{mg} /$ day and did not exceed $6 \mathrm{mg} / \mathrm{kg}$ body weight/day in any patient. Only treatment episodes initiated by the authors were recorded. Retreatments with hydroxychloroquine were considered separately-that is, as new treatment episodes. Patients receiving multiple slow acting antirheumatic drugs simultaneously were excluded, and non-steroidal anti-inflammatory drugs and corticosteroids were given as required. All patients received a regular ophthalmological 
examination, though no fixed observation protocol was used.

Reasons for the discontinuation of treatment episodes were defined as follows: inefficacy was recorded if treatment was stopped because of inadequate control of disease activity; toxicity was recorded if adverse drug effects led to the discontinuation of treatment; and remission was recorded if there was a reduction in disease activity to the extent that treatment could be withdrawn. The duration of each treatment episode was calculated from the dates of starting and stopping treatment. Life tables were constructed and compared as previously described. ${ }^{15}$ Briefly, survival probability curves were generated by the Kaplan-Meier product limit estimator. ${ }^{20}$ This method corrects for patients lost to follow up (censored) by applying the ratio of known events to the number censored in each period (one month) - that is, it assumes that those censored behaved statistically similarly to those remaining under observation.

Table 1 Demographic data for patients with rheumatoid arthritis $(R A)$ and systemic lupus erythematosus $(S L E)$

\begin{tabular}{|c|c|c|}
\hline & $\begin{array}{l}\text { Patients with } \\
R A \\
(n=366)\end{array}$ & $\begin{array}{l}\text { Patients with } \\
\text { SLE } \\
(n=37)\end{array}$ \\
\hline \multirow{2}{*}{$\begin{array}{l}\text { Female/male ratio } \\
\text { Mean (SD) age at onset (years) } \\
\text { Mean (SD) disease duration* } \\
\text { (months) }\end{array}$} & $\begin{array}{l}268: 98 \\
49 \cdot 6(15 \cdot 0)\end{array}$ & $\begin{array}{l}37: 0 \\
37 \cdot 5(16 \cdot 7)\end{array}$ \\
\hline & $4.8(6.9)$ & $6.5(5 \cdot 1)$ \\
\hline
\end{tabular}

${ }^{*}$ Duration of disease at time of starting treatment.

Table 2 Patients remaining at follow up

\begin{tabular}{lll}
\hline Time (months) & \multicolumn{2}{l}{ Number remaining at follow up } \\
\cline { 2 - 3 } & $\begin{array}{ll}\text { Patients with } \\
\text { RAt }\end{array}$ & $\begin{array}{l}\text { Patients with } \\
\text { SLEt }\end{array}$ \\
\hline 0 & 366 & 37 \\
12 & 221 & 31 \\
24 & 171 & 21 \\
36 & 140 & 19 \\
48 & 124 & 15 \\
60 & 105 & 10 \\
72 & 96 & 8 \\
84 & 94 & 4 \\
96 & 91 & 2 \\
\hline
\end{tabular}

*Time from start of treatment

$+R A=$ rheumatoid arthritis; $S L E=$ systemic lupus erythematosus

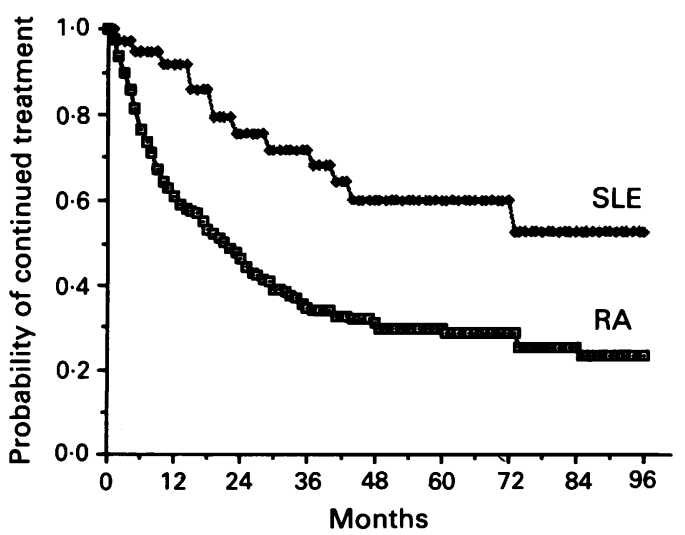

Figure 1 Cumulative probability of continuation of treatment with hydroxychloroquine in patients with rheumatoid arthritis $(R A)$ and systemic lupus erythematosus (SLE). Kaplan-Meier life tables, compared using the log-likelihood ratio statistic. Continuation probability higher log-likelihood ratio statistic. Con
in $S L E$ than in $R A, p<0.001$.
The differences between survival curves were tested statistically with a linear logistic model and the log-likelihood ratio statistic ${ }^{21}$ using the GLIM statistical package. ${ }^{22}$ This method first tests the parallelism of the life table curves and, if this is acceptable, then tests their height. Censoring in the first two years of treatment was more prevalent in patients with RA than in those with SLE, but the two groups were similar thereafter; this did not preclude the acceptability of the two life table curves for comparison purposes. $p$ Values of less than 0.05 were regarded as significant.

\section{Results}

Treatment episodes were recorded in 366 patients with RA and 37 patients with SLE. The total period of observation of treatment was 120515 days. Demographic data are recorded in table 1 and the number of subjects remaining at follow up over the eight years in table 2 .

Figure 1 shows the life tables for treatment of patients with RA and SLE with hydroxychloroquine. In patients with $\mathrm{RA}$, the highest rate of stopping treatment, represented by a steeper slope, was observed in the first year of treatment, followed by a gradual deceleration of the rate of stopping treatment over the following years. In patients with SLE a lower initial rate of stopping treatment was continued over approximately three years. The height of the SLE life table is significantly different to that in RA $(p<0.001)$. This represents a significant trend towards longer duration of treatment in this group. This is illustrated by the finding that the probability of stopping treatment with hydroxychloroquine at 12 months reached $37 \%$ in patients with RA but only $8 \%$ in patients with SLE; at 24 months the corresponding figures were 54 and $24 \%$, respectively. Figures 2 and 3 give life table data for ending the treatment episode because of inefficacy and toxicity respectively. Inefficacy was the most common reason for withdrawal, accounting for $60 \%$ of documented terminations overall (table 3 ) and occurring over an extended period. Toxicity was relatively uncommon $(13 \%)$. There were no treatment withdrawals due to ocular toxicity; the most common type of toxicity resulting in

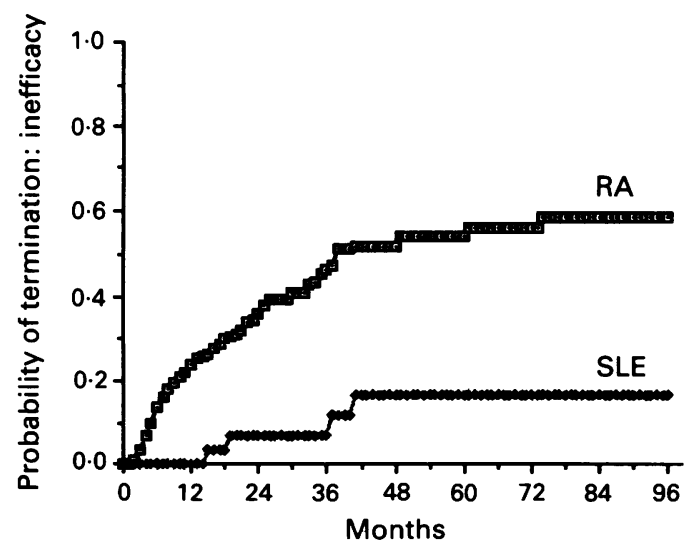

Figure 2 Kaplan-Meier life tables of cumulative probability of stopping treatment with hydroxychloroquine because of inefficacy in patients with rheumatoid arthritis $(R A)$ and systemic lupus erythematosus (SLE). 
Table 3 Indications for stopping treatment

\begin{tabular}{|c|c|c|c|c|}
\hline \multirow[t]{2}{*}{ Reason for termination } & \multicolumn{2}{|c|}{ Patients with $R A^{*}$} & \multicolumn{2}{|c|}{ Patients with SLE } \\
\hline & $n$ & $\begin{array}{l}\text { Mean }(S D) \text { duration } \\
\text { of treatmentf }\end{array}$ & $n$ & $\begin{array}{l}\text { Mean }(S D) \text { duration } \\
\text { of treatmentf }\end{array}$ \\
\hline Inefficacy & 114 & $14 \cdot 5(13 \cdot 6)$ & 4 & $27 \cdot 3(12 \cdot 6)$ \\
\hline Toxicity & & & & \\
\hline Dermatological & 14 & $2 \cdot 6(4 \cdot 8)$ & 1 & 0.6 \\
\hline Gastrointestinal & 10 & $5 \cdot 2(5.9)$ & 0 & \\
\hline Ocular & 0 & & $\mathbf{0}$ & \\
\hline All toxicity & 24 & $3 \cdot 7(5 \cdot 3)$ & 1 & 0.6 \\
\hline Remission & 46 & $15 \cdot 4(11 \cdot 3)$ & 7 & $29 \cdot 8(21 \cdot 7)$ \\
\hline
\end{tabular}

${ }^{*} \mathrm{RA}=$ rheumatoid arthritis; $\mathrm{SLE}=$ systemic lupus erythematosus.

†Months of treatment when episode stopped.

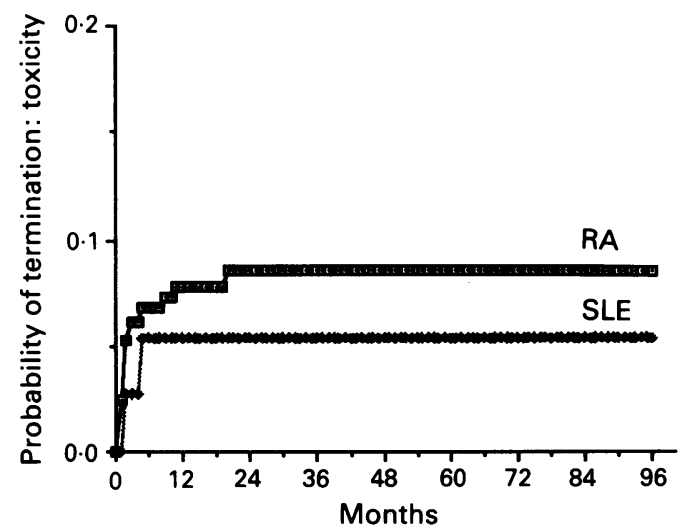

Figure 3 Kaplan-Meier life tables of cumulative probability of stopping treatment with hydroxychloroquine because of toxicity in patients with rheumatoid arthritis $(R A)$ and systemic lupus erythematosus (SLE). Note y axis range $0 \cdot 0-0 \cdot 2$

stopping of treatment was dermatological (table 3). All the cases of stopping treatment because of toxicity occurred within the first 19 months of treatment and most within six months (figure 3 ).

\section{Discussion}

Observational studies of the use of antirheumatic drugs are not perfect. Unlike controlled trials, toxicity insufficiently severe to require discontinuation of the drugs and response rates as measured by objective variables are neither recorded nor assessable. Further, observational studies assume that the results of previous prospective studies of efficacy and toxicity have been taken into account by the prescriber; in this instance, the prescriber is the head of a major university teaching hospital rheumatology unit. In clinical practice, the initiation and discontinuation of a drug tends to be on the basis of an individual 'cost-benefit' assessment; for example, a side effect may be tolerated by the patient and doctor in the face of a considerable perceived therapeutic response. In contrast, the protocols of prospective studies, where the responses to toxicity and the definition of response may be fixed, may result in a misleadingly high rate of discontinuation of the drug. Some authorities feel that the generalizability of the results of controlled studies to clinical practice cannot be assumed. ${ }^{23}$ It is self evident that the biases of the individual prescriber will have an influence on the results obtained in studies such as that reported here, but this is also true of subjects who participate in prospective trials. Although treatment termination is a complex event and does not provide a clear definition of toxicity or efficacy, it may provide a good global estimate of the long term value of a drug. ${ }^{23}$

Hydroxychloroquine is widely used for the treatment of RA. ${ }^{5624-26}$ It is generally regarded as one of the 'milder' of the slow acting antirheumatic drugs in terms of efficacy and toxicity. $^{626-29}$ Rheumatoid arthritis and SLE are chronic diseases and, in the absence of the availability of a cure, often require long term treatment. Long term studies of the use of hydroxychloroquine in RA have so far been disappointing ${ }^{12-15}$ and our findings confirm that the probability of long term continuation of treatment with hydroxychloroquine by patients with RA in community rheumatology practice is low, decreasing to $63 \%$ after only 12 months and $46 \%$ after 24 months.

In SLE, hydroxychloroquine is felt to be effective in alleviating features such as polyarthralgia, polyarthritis, skin manifestations, pleuritis, mild pericarditis and constitutional symptoms, but not in the treatment of major systemic features such as renal or central nervous system disease. ${ }^{130}$ Two studies have suggested clinical benefits associated with the long term use of hydroxychloroquine. In 1975 Rudnicki et al reported an increased incidence of constitutional and cutaneous manifestations and a greater incidence of undefined 'flares' of disease activity in patients stopping treatment with hydroxychloroquine. ${ }^{31}$ The results of a placebo controlled study of hydroxychloroquine withdrawal in stable patients with SLE have now been published. It was found that hydroxychloroquine withdrawal was associated with a relative risk of 2.5 for new or worsening manifestations of SLE, and a relative risk of $6 \cdot 1$ for 'severe' flares, over 24 weeks. ${ }^{3}$ Neither of these studies represents a controlled trial of the initiation and use of hydroxychloroquine in patients with SLE and long term prospective placebo controlled studies are needed. ${ }^{32}$ Our results over up to eight years suggest that, in patients with SLE, hydroxychloroquine has a high probability of being continued for long periods of time in most patients. The probability of continuation of treatment with hydroxychloroquine in patients with SLE was significantly different to that in patients with $\mathrm{RA}$ $(p<0.001)$, representing a significant trend towards a longer duration of treatment in this group of patients. In contrast to these results, the probability of continuing treatment with hydroxychloroquine at 12 and 24 months in patients with SLE was 92 and $76 \%$ respectively.

Toxicity has previously been shown to be an uncommon cause of the discontinuation of treatment with hydroxychloroquine in patients with RA. $\begin{array}{llllll}5 & 13 & 14 & 29 & 33-35 & \text { Our results confirm }\end{array}$ these findings in RA, and show that the same is true in patients with SLE. Ocular toxicity is cited as a major impediment to the use of hyddroxychloroquine in rheumatic diseases, yet reviews have suggested that the risk is extremely low when hydroxychloroquine is used in low 
doses. ${ }^{25} 36$ Our finding that no cases of ocular toxicity sufficient to warrant hydroxychloroquine withdrawal occurred in over 120000 treatment days calls into question the cost benefit of routine ophthalmological examinations in these patients.

The observation that most withdrawals of hydroxychloroquine in patients with RA are for inefficacy suggest one explanation for the difference in the probability of continuing treatment observed between the two diagnoses. In RA, a number of drugs such as methotrexate, sulphasalazine, D-penicillamine, and gold salts have been shown to offer clinical benefit in controlled trials. The perceived need to continue treatment with slow acting antirheumatic drugs in patients with RA may lead to a low threshold for changing treatment in the face of an insufficient clinical response. In patients with SLE, the most accepted treatment for manifestations unsuccessfully treated with hydroxychloroquine is low dose corticosteroids. ${ }^{130}$ In view of the long term side effects of corticosteroids, including osteoporosis and osteonecrosis, they may be considered undesirable by the doctor and patient. Although speculative, it is conceivable that the relative lack of alternative treatment in SLE contributes to the longer treatment duration observed.

In conclusion, we have confirmed the low probability of long term continuation of treatment with hydroxychloroquine in RA and also the extremely low prevalence of serious ocular toxicity. In contrast, in patients with SLE hydroxychloroquine was continued for extended periods with a lower probability of termination at all time points. Prospective controlled studies of hydroxychloroquine in patients with SLE are needed before the true place of this drug in the management of SLE is known, büt we have shown that patients starting treatment with hydroxychloroquine for SLE have a high probability of being able to continue with this treatment.

Dr Morand is the Michael Mason Fellow of the Arthritis Foundation of Australia and was additionally supported by Rhone Poulenc Rorer Pharmaceuticals, Australia.

1 Dubois E L. Antimalarials in the management of discoid and systemic lupus erythematosus. Semin Arthritis Rheum 1978. 8: $33-51$.

2 Mullins J F, Watts F L. Plaquenil in the treatment of lupus erythematosus. $\mathcal{F A M A}$ 1956; 161: 879-81.

3 Canadian hydroxychloroquine study group. A randomized study of the effect of withdrawing hydroxychloroquine sulfate in systemic lupus erythematosus. $N$ Engl f Med 1991; 324: $150-4$.

4 Felson D T, Anderson J J, Meenan R F. The comparative efficacy and toxicity of second-line drugs in rheumatoid arthritis. Results of two metanalyses. Arthritis Rheum 1990; 33: 1449-61.

5 Maksymowych W, Russell A S. Antimalarials in rheumatology: efficacy and safety. Semin Arthritis Rheum 1987; 16: 206-21.

6 Runge L A. Antimalarials. In: McCarty D J, ed. Arthritis and allied conditions. 11th ed. Philadelphia: Lea and Febiger, 1989: 556-62.
7 Runge L A. Risk/benefit analysis of hydroxychloroquine sulfate treatment in rheumatoid arthritis. Am $\mathcal{F}$ Med 1983; 75 (suppl 1A): 52-6.

8 Freedman A, Steinberg V L. Chloroquine in rheumatoid arthritis. A double blindfold trial of treatment for one year. Ann Rheum Dis 1960; 19: 243-50.

9 Freedman A. Chloroquine in rheumatoid arthritis. A short reedman A. Chloroquine in rheumatoid arthritis. A short
term controlled trial. Ann Rheum Dis 1956; 15: 251-9.

term controlled trial. Ann Rheum Dis 1956; 15: 251-9.
10 Nuver-Zwart I H, van Riel P L C M, van de Putte L B A Gribnau $F$ W J. A double blind comparative study of sulphasalazine and hydroxychloroquine in rheumatoid arthritis: evidence of an earlier effect of sulphasalazine. Ann Rheum Dis 1989; 48: 389-95.

11 McCarty D J. Suppress rheumatoid inflammation early and leave the pyramid to the Egyptians. $\mathcal{J}$ Rheumatol 1990; 17 : 1115-7.

12 Wolfe F, Hawley D J, Cathey M A. Termination of slow acting antirheumatic therapy in rheumatoid arthritis: a 14 year prospective evaluation of 1017 consecutive starts. f Rheumatol 1990; 17: 994-1002.

13 Husain Z, Runge LA. Treatment complications of rheumatoid arthritis with gold, hydroxychloroquine, D-penicillamine arthritis with gold, hydroxychloroquine, D-pen
and levamisole. I R heumatol 1980; 7: 825-30.

14 Richter J A, Runge L A, Pinals R S, Oates R P. Analysis of treatment terminations with gold and antimalarial com-

15 Morand E F, McCloud P I, Littlejohn G O. Life table analysis of 879 treatment episodes with slow-acting antirheumatic drugs in community rheumatology practice. f Rheumatol 1992; 19: 704-8.

16 Hawley D J, Wolfe F. Are the results of controlled clinical trials and observational studies of second line therapy in rheumatoid arthritis valid and generalizable as measures of rheumatoid arthritis outcome: analysis of 122 studies. f Rheumatel 1991; 18: 1008-14

17 Ropes M W, Bennet G A, Cobb S, Jacox R, Jessar R A. The 1958 revision of diagnostic criteria for rheumatoid arthritis. Bull Rheum Dis 1958; 9: 175-6.

18 Arnett F C, Edworthy S M, Bloch D A, et al. The American Rheumatism Association 1987 revised criteria for the Rheumatism Association 1987 revised criteria for the
classification of rheumatoid arthritis. Arthritis Rheum 1988; classification

19 Tan E M, Cohen A S, Fries J F, et al. The 1982 revised criteria for the classification of systemic lupus erythematosus. Arthritis Rheum 1982; 25: 1271-7.

20 Chambers J M, Cleveland W S, Kleiner B, Tuhey P A Graphical methods for statistical analysis. Belmont: Wadsworth International, 1983: 233-6.

21 Cox D R, Oakes D. The analysis of survival data. London: Charman and Hall, 1984.

22 Payne R W. The GLIM system. Oxford: Numerical Algorithms Group Limited, 1987.

23 Felson D T. Clinical trials in rheumatoid arthritis under attack: are practice based observational studies the answer? attack: are practice based obse.

24 Tett $S$, Cutler D, Day R. Antimalarials in rheumatic diseases. Ballieres Clin Rheumatol 1990; 4: 467-89.

25 Mackenzie A H, Sherbel A L. Chloroquine and hydroxychloroquine in rheumatological therapy. Clin Rheum Dis 1984; 6: 545-67.

26 Bellamy $\mathbf{N}$, Brooks $P$ M. Current practice in antimalarial drug prescribing in rheumatoid arthritis. $\mathcal{f}$ Rheumato 1987; 13: 551-5.

27 van Saase J, Vandenbrouke J, Valkenberg $\mathrm{H}$, et al. Changing pattern of drug use in relation to disease duration of rheumatoid arthritis. $\mathcal{F}$ Rheumatol 1987; 14: 476-8.

28 Rynes R I. Hydroxychloroquine treatment of rheumatoid arthritis. Am F Med 1988; 85 (suppl 4A): 18-22.

29 Paulus $H$ E. Antimalarial drugs compared with or in combination with other disease-modifying antirheumatic drugs. Am 7 Med 1988; 85 (suppl 4A): 45-52.

30 Wallace D J, Dubois E L. Management of discoid and systemic lupus erythematosus. Dubois' lupus erythematosus. systemic lupus erythematosus. Dubois' lupus erythematosus

31 Rudnicki R D, Gresham G E, Rothfield N F. The efficacy of antimalarials in systemic lupus erythematosus. $\mathcal{F}$ Rheumato 1975; 2: 323-30.

32 Lockshin M D. Therapy for systemic lupus erythematosus [editorial]. N Engl f Med 1991; 324: 189-91.

33 Bunch T W, O'Duffy J D, O'Fallon W M. Controlled trial of hydroxycloroquine and D-penicillamine singly and in combination in the treatment of rheumatoid arthritis. Arthritis Rheum 1984; 27: 267-76.

34 Bunch $T$ W, O'Duffy J D. Disease modifying drugs for progressive rheumatoid arthritis. Mayo Clin Proc 1980; 55: 161-79.

35 Adams E M, Yocum D E, Bell C L. Hydroxychloroquine in the treatment of rheumatoid arthritis. Am $\mathcal{F}$ Med 1983; 75: the treat 6 .

36 Easterbrook $M$. Ocular effects and safety of antimalarial agents. Am $\mathcal{F}$ Med 1988; 85: 23-9. 